\title{
Acesso aos serviços de saúde: uma possibilidade a ser construída na prática
}

\author{
Access to health services: \\ a possibility of enabling it in practice
}

Marluce Maria Araújo Assis 1

Tereza Cristina Scatena Villa 2

Maria Angela Alves do Nascimento 1

\footnotetext{
1 Departamento de Saúde, Universidade Estadual de Feira de Santana Km 3, BR 116. Campus Universitário. 44031-460, Feira de Santana BA. aassis@uefs.bre marluceassis@bol.com.br

2 Universidade de São Paulo.
}

\begin{abstract}
This qualitative study on users access to the Basic Health Services in Feira de Santana, Bahia State, Brazil, had the purpose to analyse the perception of the users when it comes to the caracteristics of the services used in local health system, articulating theory and practice in order to find possibilities based on users citizens' rights. The theoretical framework was based on authors that analyzed the explicative dimensions of access (political, economic, technical and symbolic) articulated with the social representation theoretical model. The empirical data comprehended the observation of access in two health centers and interviews with 25 users. The analysis aimed at meeting the "empirical reality". Results showed that the access to services is focussed and selective to respond to a specific complaint, that they are technologically delayed and discriminatory services, directed to the low income user and to the socially excluded population.
\end{abstract}

Key words Access, Basic services, Health system
Resumo Estudo qualitativo sobre o acesso dos usuários às unidades básicas de Feira de Santana (BA), com o objetivo de analisar a percepção dos usuários quanto às características dos serviços utilizados no sistema local de saúde, articulando teoria à prática com vistas a uma possibilidade a ser construida como direito de cidadania. O referencial teórico foi baseado em autores que analisam as dimensões explicativas do acesso (política, econômica, técnica e simbólica), articuladas com o modelo teórico da representação social. Os dados empíricos foram a observação do acesso em dois centros de saúde e a entrevista com 25 usuários atendidos nos referidos centros. A análise buscou um encontro com a realidade empírica. Os resultados mostram que o acesso aos serviços é focalizado e seletivo para responder a uma determinada queixa, tecnologicamente atrasado e discriminatório, dirigido ao usuário de baixa renda que tem menor qualificação no setor formal da economia e à população excluída socialmente.

Palavras-chave Acesso, Unidades básicas, Sistema de saúde 


\section{Introdução}

O presente estudo tem como objetivo analisar as condições de acesso dos usuários às unidades básicas de saúde de Feira de Santana (BA), articulando teoria à prática com vistas a uma possibilidade a ser construída como direito de cidadania.

O conceito de saúde assegurado na legislação brasileira constitui-se como um direito da cidadania a ser garantido pelo Estado e a universalidade da atenção implica, necessariamente, a formulação de um modelo social ético e equânime norteado pela inclusão social e solidariedade humana. Nesse sentido, o impasse vivenciado com a concretização do acesso universal aos serviços de saúde requer uma luta constante pelo fortalecimento da saúde como um bem público, e da edificação de uma utopia social igualitária, tendo a saúde como direito individual e coletivo que deve ser fortalecido com o redimensionamento de uma nova prática construída a partir de uma gestão democrática e participativa.

Todavia, entendemos a necessidade de esforços dirigidos a lutas cotidianas por um novo modelo que priorize a promoção da saúde,e que também possa dar conta da demanda por atendimento à doença com mudanças sociais $\mathrm{e}$ institucionais inovadoras que reorientem as políticas de saúde e a organização dos serviços (públicos e privados).

Esse modelo deve incluir dois eixos teóricos: um que incorpore os determinantes sociais do processo saúde-doença em uma perspectiva de atenção integral às necessidades da população, e outro que reafirme a saúde como um bem público a partir da efetivação de práticas e serviços de saúde como sendo de relevância pública, cabendo ao Estado a sua regulação e controle, independente do regime de propriedade de quem produz os serviços, se público ou privado.

A dura verdade se revela como aprendizagem na organização do sistema de saúde, "não se cria igualdade por lei, ainda que não se consolide a igualdade sem a lei" (Fleury, 1997). Até mesmo porque no cenário nacional convivemos com acessos seletivos, excludentes e focalizados que se complementam e se justapõem nos diferentes serviços públicos e privados, havendo, portanto, um descompasso entre a legislação e a legitimidade social.

Para Campos (1991, 1992), Giovanella e Fleury (1995), Barros (1996) e Assis (1998), o seletivo se refere à desigualdade de acesso e distribuição de benefícios em função do poder de compra do usuário, seja pelo desembolso direto cliente-profissional, ainda que em pequena escala, ou pelos contratos estabelecidos por seguradoras de saúde ou cooperativas médicas, considerados a medicina supletiva. Medicina essa gerida pela lógica do mercado, dispondo de várias modalidades assistenciais que abarcam desde planos individuais, familiares ou de responsabilidade da empresa. Há uma seleção social $a$ priori pela relação estabelecida entre os preços dos serviços e a capacidade de compra do cliente e/ou empresa, estando o consumidor à mercê da autoridade dos empresários da saúde para determinar quanto e o que deve consumir. O consumidor em potencial é a classe média, representada por aproximadamente " $22 \%$ " do mercado" (Mendes, 1994).

Excludente, por ser pautado na lógica do mercado e condicionar o direito à assistência universal aos mecanismos de racionamento dos gastos que têm como conseqüência a deterioração da qualidade da atenção prestada nos serviços públicos, excluindo os grupos sociais que têm um maior poder de organização na sociedade, a exemplo dos funcionários de indústrias, bancários e outros, que apresentam nas suas pautas de reivindicações sociais as novas formas de financiamento do sistema de atenção médica supletiva, representada pelas cooperativas médicas e os seguros privados de saúde.

$\mathrm{O}$ acesso é focalizado, ao restringir o atendimento público a determinados serviços ou programas, e a universalização da atenção se traduz em um sistema segmentado e desarticulado no âmbito interno do sistema público e na cadeia organizativa do sistema como um todo.

\section{Referencial teórico}

A discussão teórica apontada por Giovanella \& Fleury (1995) toma como eixo de análise quatro dimensões explicativas: a política, a econômica, a técnica e a simbólica. A dimensão política considera as relações que se estabelecem entre as políticas de saúde e a conformação histórica do modelo de atenção à saúde que envolve a possibilidade de desenvolver a consciência sanitária e a organização social; a econômica se refere à relação entre oferta e demanda; a técnica exprime, por um lado, a utilização e as dificuldades do usuário para concretizar $\mathrm{o}$ atendimento pretendido e, por outro, a 
oferta dos serviços de saúde, o seu planejamento, a sua organização (que recursos dispõe), o fluxo, a qualidade e a resolutividade do serviço produzido; a dimensão simbólica é relativa às representações sociais acerca do processo saúde-doença e da forma como o sistema se organiza para atender às necessidades dos usuários.

As autoras buscam nas dimensões explicativas caracterizar a categoria acesso e analisar as condições de acessibilidade, na tentativa de articular o referencial teórico e a definição conceitual a ser utilizada. Para isso, nomeiam quatro modelos teóricos evidenciados a partir de outros estudos e da legislação brasileira: o economicista, o sanitarista-planificador, o sanitarista-politicista e o da representação social.

O modelo economicista é explicitado ao conformar a demanda através da diferenciação dos distintos grupos populacionais no acesso aos bens e serviços de saúde; a relação ofertademanda é moldada na forma de organização da assistência médica.

O sanitarista-planificador conforma-se pela ação planejadora do Estado a partir da garantia da localização adequada, da disponibilidade e da articulação funcional dos serviços em uma rede organizada de acordo com a demanda.

As autoras inspiradas em Berlinguer (1978) discutem o modelo sanitarista-politicista tomando como conceito-chave a noção de consciência sanitária, que implicaria um componente cognitivo através do qual a população compreende a determinação social do processo saúde-doença e, da mesma forma, os fatores que determinam a organização social das práticas de saúde.

Por fim, o modelo teórico da representação social, eixo recortado no presente estudo, toma a linguagem como "matriz originária da realidade social e psíquica" (Birman, 1991), constituída como campos de objetividade pela ordem simbólica. Isso implica compreendê-la pela mediação da ordem simbólica em sua significação e apreensão por parte dos sujeitos e grupos sociais, portadores de história, tradição e cultura.

Complementa Herzlich (1991) que as representações sociais da saúde e da doença estão relacionadas às nossas visões do biológico e do social. São, portanto, enraizadas na realidade social e construídas historicamente pela sociedade e manifestadas em representações coletivas. Afirma, ainda, que no campo da doença a representação não é apenas um esforço de for- mulação mais ou menos coerente de um saber, mas uma questão de sentido que emerge de uma desordem; a doença, que adquire significação: por ser um evento que ameaça ou modifi$c a$, às vezes irremediavelmente, nossa vida individual, nossa inserção social e, portanto, o equilíbrio coletivo, a doença engendra sempre uma necessidade de discurso, a necessidade de uma interpretação complexa e contínua da sociedade inteira (Herzlich, 1991).

\section{Metodologia}

Esta pesquisa constitui-se em uma abordagem qualitativa, conforme orientações de Minayo (1993), propondo-se à compreensão de uma realidade específica, fundamentada em dados empíricos através das técnicas de observação livre e da entrevista focalizada na seguinte questão orientadora: Como o senhor(a) faz para ter acesso aos centros de saúde da rede pública de Feira de Santana?

A entrevista possibilitou uma interlocução entrevistador-entrevistado contribuindo para o desenvolvimento do tema proposto. Como técnica de coleta de dados, valoriza a presença do investigador e favorece ao informante a liberdade e a espontaneidade necessárias para o enriquecimento da investigação (Trivinõs, 1992).

Os entrevistados foram escolhidos de forma aleatória no momento da observação, sendo ao todo 25 pessoas. A escolha dos depoimentos para compor a representação dos discursos no corpo do trabalho se deu pelo critério de similaridade das respostas, após definir os trechos das falas, estabelecemos a ordem numérica dos entrevistados (Entrevistado $\mathrm{n}^{\circ} . .$. ), sendo escolhidos, ao todo, seis entrevistados que representavam as convergências dos discursos sobre a temática em questão.

As observações foram realizadas em dois centros de saúde, perfazendo um total de 24 horas de observação. Na escolha das instituições consideramos as suas posições na hierarquia da estrutura organizativa, por serem "porta de entrada" do sistema (pelo menos no plano do ideal), no qual deveria se dar o primeiro contato do usuário com a rede. Atentamos para a oferta e produção dos serviços e a resolutividade do problema apresentado pelo usuário.

Optamos por um tipo de observação, em que situa o pesquisador como observador: num instante tão importante para a investigação, in- 
felizmente não se podem dar orientações precisas sobre modos de atuar e proceder. Cada situação tem suas próprias características. E o investigador deve avaliar as circunstâncias e buscar o melhor caminho (Trivinõs, 1992).

Nessa perspectiva, a observação não é neutra, permitindo ao pesquisador e observados uma relação de troca temporária que envolve diálogo em torno da "objetividade" e "subjetividade" do problema em estudo, permitindo uma interlocução (sujeito e objeto do conhecimento) durante o trabalho de campo.

$\mathrm{Na}$ análise e tratamento do material empírico enfatizamos principalmente, o encontro da especificidade do objeto pela prova do vivido e sua articulação com o modelo teórico de representação social discutido por Giovanella e Fleury (1995), representado nas minúcias dos fatos relatados pelos sujeitos sociais em situações concretas.

Estas situações são representadas no texto por cenários, analisados a seguir.

\section{Análise e discussão dos resultados}

\section{Cenário um}

Os dados concretos sobre o acesso dos usuários aos serviços de saúde retirados da tese de doutorado de uma das autoras deste estudo (Assis, 1998) permitiram caracterizar o Cenário um, descrevendo as observações realizadas em um centro de saúde da rede municipal pública da cidade de Feira de Santana (BA).

$\mathrm{Na}$ entrada do centro tem cartazes informando o dia e o horário do atendimento dos trabalhadores de saúde (médico e dentista), da oferta de serviços, inclusive horários de palestras.

Os outros serviços produzidos diariamente não são destacados em cartazes. As enfermeiras realizam a puericultura nos dois turnos - manhã e tarde -, além do planejamento familiar e do pré-natal.

A marcação da consulta do clínico é na segunda-feira para que o usuário seja atendido na terça e na quarta-feira. A consulta não pode ser agendada de uma semana para outra. O pediatra e o ginecologista não fazem agendamento, o atendimento é realizado pela ordem de chegada.

No que diz respeito ao grau de resolutividade do serviço, observamos que as pessoas que procuraram o programa de imunização saíam satisfeitas com o tipo de atendimento oferecido, assim como a consulta realizada pela enfermeira na sala de puericultura (o atendimento era em média de 15 minutos). Com relação ao atendimento médico, as pessoas reclamavam da demora no atendimento, de várias idas ao centro para conseguir ser atendida, porém mencionam gostar da consulta do clínico. Quanto ao pediatra, algumas pessoas reclamavam e só o procuravam porque não tinham outra alternativa. Ainda foi possível perceber que os usuários eram atendidos em função de uma queixa, não havia garantia de exames, ou mesmo da continuidade do tratamento. No que se refere ao dentista, as pessoas reclamavam das faltas ao trabalho, porém consideravam um atendimento de qualidade.

Os usuários procuravam o centro de saúde na dependência da oferta:

- Consulta médica - clínico, pediatra e ginecologista;

- Atendimento odontológico - com queixa de dor de dente, para primeira consulta ou para fazer exame de rotina;

- Atendimento nos programas de imunização e puericultura.

$\mathrm{O}$ acesso envolve demandas diferenciadas por tipo de atendimento ofertado, havendo interposições de usuários que utilizam os serviços públicos e os privados, como é o caso dos que procuram o centro de saúde somente para vacinação por indicação do médico do convênio, mas quando necessitam de consultas médicas ou exames para apoio diagnóstico e terapêutico recorrem a convênios médicos, justificados nos discursos a seguir:

Sabe, meu plano cobre todo exame, consulta e internamento. Meu marido paga um dinheirão, porque a gente não quer passar pelos vexames em hospitais... Eu só vim aqui vacinar porque meu médico disse que vacina só serve do Posto, por isso eu vim. (Entrevistado no 1)

Eu venho aqui no Posto só pra vacinar meus filhos, minha família tem o Saúde Bradesco. A vantagem que tem o Plano é que se a gente não gostar daquele médico a gente troca e acabou e não fica devendo favor a ninguém, porque eu pago todo mês, não é? Agora, se eu e minha família precisássemos somente dos estabelecimentos públicos, tenho certeza de que as coisas seriam diferentes, porque eu vejo o quanto o povo sofre nas filas, dorme até na porta dos consultórios médicos e dos laboratórios pra fazer qualquer exame. Eu sempre peço a Deus que nunca deixe eu precisar de nada do governo porque é um desgaste 
muito grande e um sofrimento, e a gente não pode nem brigar porque é de graça. (Entrevistado no 2)

Seria importante comentar os referidos discursos que são bastante significativos da ambigüidade do modelo de organização do sistema pautado nos princípios da reforma sanitária que teoricamente prega a universalidade do sistema público, mas na prática, a correlação de forças hegemônicas busca ganhar aliados para as estratégias que são capazes de gerar soluções corporativas que privilegiam os setores mais qualificados da classe trabalhadora, selecionando a clientela por meio de um sistema adicional de seguros privados, segmentando-as, inculcando-se inclusive nos usuários a falência do sistema público, que também é reforçado pela mídia, com manchetes que exploram somente os problemas e dificuldades e não os avanços conseguidos no processo de democratização da saúde, mesmo reconhecendo, que existem muitas dificuldades a serem superadas.

Não concordamos com o argumento de que as pessoas estão optando por convênios médicos pela facilidade de acesso a serviços especializados, ou exames que envolvem tecnologia de ponta porque, na realidade, não existia, até 1998, uma lei que delimitasse o raio de ação dos planos privados e as empresas ofereciam o que bem entendessem para os usuários, excluindo agravos de alto custo que não dessem uma grande margem de lucro, a exemplo dos tratamentos para renais crônicos, as doenças transmissíveis, as emergências médicas, transplantes de órgãos, entre outros; cabendo ao SUS o atendimento dessas patologias com um volume de recursos "em torno de 30\% do financiamento” (Mendes, 1994; Assis, 1998).

\section{Cenário dois}

O acesso ao serviço nesse centro de saúde da rede pública estadual se organiza de forma diferente do anterior. A grande maioria da demanda é para especialidades médicas por ser um Centro de Atendimento Especializado que conta com clínica geral, pediatria, ginecologia, obstetrícia, endocrinologia, otorrino, reumatologia, dermatologia, ortopedia, pneumologia, gastroenterologia, alergia, urologia e cardiologia; além dos programas de saúde, tais como Planejamento Familiar, Diabetes, Hipertensão, Imunização e Pré-natal.

Observamos uma demanda massiva, tendo em vista que as longas filas se arrastavam pelos corredores e escadas da unidade.
Os usuários se dirigiam diretamente ao balcão de marcação de consultas, onde recebiam uma senha e aguardavam para serem atendidos. As filas se organizavam de duas formas: consultas por especialidade médica e marcação de exames para apoio diagnóstico e terapêutico em laboratórios, clínicas ou hospitais conveniados com o SUS. A consulta só poderia ser marcada para o prazo de até oito dias. Algumas pessoas informaram que estavam na fila desde às quatro horas da manhã. As que chegaram muito cedo conseguiram marcar suas consultas.

Os depoimentos dos usuários a seguir coadunam com as observações realizadas nos serviços de saúde, confirmando que a lei ainda é uma possibilidade de concretização de uma prática social:

... eu vim aqui segunda-feira, procurei o clínico e não tinha, porque dia de segunda depois que eu soube não tem médico, vim na terça também e o clínico faltou... Aí eu voltei hoje (uma semana depois) e já estou com a ficha. Sempre venho aqui e quando encontro ficha sou atendida e quando não encontro venho até conseguir, as pessoas que trabalham aqui são muito atenciosas e tratam a gente bem, o problema é que nunca tem médico. (Entrevistado no 3)

... Eu vim aqui vacinar minha filhinha, porque já fui várias vezes no Posto perto de casa e não tinha vacina de tuberculose. Olhe que maravilha, cheguei não tinha fila e elas, as enfermeiras, me atenderam num instante. Agora eu vou dizer as minhas amigas e meus parentes lá da Mangabeira pra eles virem pra cá, você não acha? (Entrevistado no 4)

... Você chega no Posto com um filho arrebentado, quer fazer um curativo, ah não tem esparadrapo, não tem uma antitetânica, não tem gases. A gente já vai no Posto porque não tem condições de pagar particular porque tem que se virar pra comprar tudo se quiser ver aquela pessoa com o estado bom de saúde, não é? E está praticamente abandonado, você chega atrás de um dentista, não tem. Você procura um médico, não tem... (Entrevistado no. 5).

...Sabe, eu sou deste Programa de Diabetes, $e$ eu soube deste programa através de uma amiga que é minha vizinha e trabalha aqui. Tem dois anos que estou sendo atendida aqui e estou muito satisfeita... (Entrevistado no 6)

As convergências nos discursos dos entrevistados foram visualizados por uma das autoras no momento da observação de que a universalização da atenção se traduz em um sistema segmentado e desarticulado no âmbito in- 
terno do sistema público e na cadeia organizativa do sistema como um todo. O acesso é definido não em função de uma oferta de serviços organizada e hierarquizada, e sim pelas necessidades estabelecidas pelos usuários. Essas "necessidades" são representadas de várias formas: a) necessidade de atenção médica ou odontológica para tratar um agravo já instalado, envolvendo o atendimento emergencial, as doenças crônico-degenerativas (no caso, os Programas de Diabetes e Hipertensão Arterial) ou outras necessidades centradas no processo de cura individual, e para prevenção de doenças através da imunização;

b) resolução da queixa apresentada pelo usuário;

c) atenção que a equipe dispensa aos usuários, garantindo o atendimento, ainda que seja através de uma longa espera;

d) localização geográfica da unidade de saúde. Em uma região central, facilita o acesso às pessoas que vêm de outras cidades circunvizinhas; e) disponibilidade de recursos humanos enfatizando a "figura do médico" para resolver um problema imediato;

f) credibilidade do serviço alcançada junto aos usuários, referenciada por pessoas que usufruíram ou usufruem a produção desse serviço, além da veiculação pelos meios de comunicação;

g) indicação de amigos e parentes que conhecem o serviço produzido.

\section{Representações dos usuários sobre o acesso aos serviços de saúde}

Nesta parte do trabalho, estabelecemos as representações sociais dos usuários sobre o acesso aos serviços de saúde, tomando como eixo orientador a análise de Giovanella e Fleury (1995) que enfatiza as dimensões política, econômica, técnica e simbólica, buscando uma unidade de relação do usuário com os serviços de saúde.

A representação da dimensão econômica é explicitada pela forma de acesso aos bens e serviços de saúde dos distintos grupos populacionais, em que a relação oferta-demanda é moldada na forma de organização da assistência médica; ou seja, os usuários delimitam o acesso à sua condição socioeconômica, pois consideram que a oferta dos serviços públicos fica na dependência da capacidade de intervenção do Estado na organização da rede de atendimento.
A questão é discutida por Mendes (1994) ao se referir ao "universalismo excludente" como um dos mecanismos de racionamento do sistema público de saúde, especialmente a queda da qualidade dos serviços, que concomitantemente vêm expulsando do sistema público segmentos sociais de camadas médias e do operariado urbano mais qualificado.

Dessa forma, concordamos com o autor que o princípio da universalidade, garantido em lei, é reinterpretado na prática social não como um universalismo inclusivo, como direito de cidadania, mas como um universalismo excludente, expressado em oferta de serviços limitantes e de baixa resolubilidade.

... o acesso é muito difícil no serviço público, só vem quem não tem como pagar; são os pobres, os miseráveis; quem tem dinheiro vai ao médico particular. Também tudo que é do Estado é assim, não tem qualidade, por isso têm aumentado tanto as clínicas privadas na cidade. (Entrevistado no 4)

Ao relacionar a representação dos usuários que são atendidos na rede básica de saúde de Feira de Santana, é preciso considerar a dimensão política que orienta o acesso, como responsabilidade do Estado, que deve ser garantido pela distribuição planejada de recursos da rede de serviços, levando em conta a localização geográfica da unidade, a disponibilidade dos serviços e a articulação entre os serviços que compõem a rede, de acordo com as demandas e necessidades da população. Significa, portanto, que a realidade estudada articula-se ao cenário nacional (Barros, 1996; Campos, 1991, 1992), ao não incorporar as matrizes básicas que servem de suporte para um modelo de saúde público e universal, conforme documento do Ministério da Saúde (Brasil, 1990):

- regionalizada, com as unidades distribuídas espacialmente na proximidade do local de trabalho e moradia, levando-se em conta as condições de transporte;

- hierarquizada de acordo com os diferentes níveis de complexidade equipados com recursos necessários para garantir resolubilidade;

- com agilidade nos processos administrativos para facilitar o atendimento da demanda e com a oferta de serviços em compatibilidade com a maior possibilidade de utilização pelos usuários;

- garantindo a informação adequada aos usuários sobre os serviços e os procedimentos para sua utilização;

- com um sistema de organização baseado 
nos princípios de referência e contra-referência, viabilizando o fluxo ágil dos usuários no interior dos distintos níveis de complexidade do sistema de saúde.

O depoimento abaixo traduz essas afirmativas:

.... muitas vezes, o indivíduo é atendido de manhã no Posto de Saúde, de tarde ou de noite no Pronto Socorro, porque nada é planejado. Quer dizer, no meu modo de ver triplica a ação, porque o atendimento não é organizado para atender o que as pessoas necessitam. Sem falar na distância do Posto, porque agente vai onde melhor atende. (Entrevistado no 5)

Nas falas dos entrevistados também foi possível observar a percepção do processo saúde/enfermidade como componente cognitivo que determina a organização social das práticas de saúde.

Nessa perspectiva, recorremos a Berlinguer (1978) que analisa o acesso aos serviços de saúde, tomando como conceito chave a noção de consciência sanitária que seria a tomada de consciência de que a saúde é um direito da pessoa e um interesse da comunidade. Mas como esse direito é sufocado e esse interesse, descuidado; consciência sanitária é ação individual e coletiva para alcançar este objetivo.

O processo de politização do sujeito pressupõe o rompimento com o modelo de saúde centrado na cura individual e nos interesses particulares construídos historicamente pela sociedade. Para (des)construir essa lógica de atenção individual e privatizada, na tentativa de vislumbrar um sistema de saúde público, coletivo, universal e igualitário, é preciso envolver governo, trabalhadores de saúde e usuários, por meio da participação social consciente na gestão e no controle social do sistema.

Infelizmente, os depoimentos dos usuários apontam um cenário desalentador no acesso aos serviços de saúde, que muitas vezes se dá após uma cobrança de taxa por fora ou até mesmo, pela interferência político-partidária:

Se precisamos de qualquer serviço que é encaminhado pelo centro de saúde, é uma dificuldade para receber o atendimento, se chega num laboratório que tem convênio com o SUS, tem de pagar uma taxa por fora para ser atendido e tem de chegar 4 horas da manhã, ou até dormir na porta, ou então depender de algum politico para conseguir o atendimento. O centro oferece alguns serviços, mas quando precisamos de um serviço mais complexo não temos acesso, só quem paga plano de saúde ... (Entrevistado no 5)
Reforçamos, conforme explicitado anteriormente, a necessidade de politização das demandas, compreendida a partir do desvendamento da realidade que passa a apreender as contradições centrais do processo de produção, que envolve a luta de classes sociais para a formação de uma contra-hegemonia, através da construção de um saber e de uma força social capaz de cobrar o cumprimento da legislação, de participar efetivamente do processo de mudança na organização do sistema de saúde que contemple a universalidade do acesso, com responsabilidade social.

No entanto, a luta política e ideológica dos defensores do projeto neoliberal para a saúde no Brasil é evidenciada por forças políticas que dão sustentação ao referido projeto e vêm estabelecendo estratégias apoiadas em dois eixos: estender até os seus limites máximos a medicina de mercado, relativamente independente do Estado. Estima-se que essa alternativa teria uma demanda potencial de 20 a 25\% da população brasileira... Ao mesmo tempo, essa articulação busca ampliar a atenção individual curativa para além da fatia populacional economicamente apta a se inserir em uma das modalidades privadas de assistência, disputando, com esse fim, o recurso público agora sob controle do SUS (Campos, 1992).

Para os usuários dos serviços de saúde a representação social do processo saúde-doença é feita, em última instância, pela prática médica, na qualidade de saber dominante no campo da organização das práticas de saúde, saber este que adquire sentido e significado a partir de uma desordem, de uma doença que poderia ser explicada: “... por ser um evento que ameaça ou modifica... nossa vida individual, nossa inserção social e, portanto, o equilíbrio coletivo..." (Herzlich, 1991). E os conflitos são interpostos pela doença e pela prática médica, como partes do cotidiano das classes e grupos sociais e como componentes sociais de dominação e resistência (Minayo, 1993).

Eu só vim aqui vacinar porque meu médico disse que vacina só serve do Posto, por isso estou aqui, senão vacinava na clínica do meu médico... Eu tenho plano de saúde que cobre todo exame, consulta e internamento. (Entrevistado no 1 )

Eu venho aqui no Posto só pra vacinar meus filhos, minha família tem o Saúde Bradesco. A vantagem que tem o Plano é que se a gente não gostar daquele médico a gente troca e acabou... (Entrevistado no 2)

O processo saúde-doença, por um lado, é conformado pelas raízes históricas e culturais 
socialmente construídas e reinterpretadas pelos indivíduos e grupos sociais, de acordo com suas concepções de mundo, suas condições de existência, seus interesses específicos e sua inserção na organização de uma determinada sociedade, por outro, as práticas desenvolvidas no cotidiano dos serviços tomam como base o sistema de crenças vigente sobre o processo saúde/doença que é pautado no paradigma biomédico.

Mendes Gonçalves (1992) destaca dois modelos de práticas complementares e não excludentes: o modelo clínico, baseado na clínica anatomopatológica, no qual a doença pode ser admitida como influenciada pela vida de relação do doente, mas como fenômeno positivo é recortada exclusivamente no espaço de seu corpo individual e o modelo epidemiológico, que concebe a doença como fenômeno coletivo e busca controlála em escala social relativamente ampla e efetiva.

A complementaridade desses dois modelos diz respeito à possibilidade de cada um deles responder com eficácia às necessidades sociais demandadas pelos usuários referentes ao processo saúde-doença, sendo ambos imprescindíveis, apesar de sua desigual valoração técnicosocial. Assim, os profissionais de saúde (médico, psicólogo, enfermeiro...) estão colocados, em alguma medida, diante da necessidade de apreenderem e entenderem a saúde e a doença como fenômenos sociais que envolvem as dimensões individual e coletiva.

Para Peduzzi (1998), a nenhum profissional de saúde, em particular, cabe a possibilidade de projeção e execução da totalidade de ações demandadas pelos usuários, embora permaneça mantida a centralidade do modelo médico de assistência, visto que ao profissional médico cabe a ação nuclear da definição diagnóstica e terapêutica, representando este, portanto, o principal mediador entre as necessidades dos usuários e a oferta de serviços.

A esse respeito, enfatizamos a importância de compreender o profissional médico e as outras profissões complementares, como sujeitos sociais que ocupam vários espaços no campo da saúde, sejam como dirigentes, empresários ou trabalhadores de saúde e que vêm construindo historicamente, um espaço de poder ideológico e político, dando "homogeneidade à classe dominante", um pouco em analogia ao pensamento de Gramsci (1995), quando atribui aos "intelectuais orgânicos" a edificação dos seus quadros e dos seus elaboradores de ideologia da classe econômica e politicamente dominante. Ou seja, o sustentáculo sobre o qual se desenvolveu a ideologia neoliberal no campo da saúde foi gestado na própria conformação organizativa do sistema de saúde brasileiro que sempre impôs à sociedade uma cidadania restrita e regulada, criando condições para se reproduzir na prática uma estrutura de serviços que prioriza a privatização em dissonância com a legislação sanitária.

Concluímos que a situação concreta apresentada, mesmo reconhecendo que é uma realidade na maioria dos municípios brasileiros, constitui-se de serviços focalizados e seletivos para responder uma determinada queixa, tecnologicamente atrasados, dirigidos ao usuário de baixa renda que tem menor qualificação no setor formal da economia e à população excluída socialmente. Ainda que haja processos instituintes, criando espaços de construção de práticas alternativas ao modelo dominante, como é o caso dos Programas de Saúde das unidades observadas, que têm possibilitado ações humanizadas e acolhedoras junto aos usuários com um grau relativo de resolutividade na cadeia do sistema de saúde. 


\section{Referências bibliográficas}

Assis MMA 1998. As formas de produção dos serviços de saúde: o público e o privado. Tese de doutorado. Escola de Enfermagem de Ribeirão Preto, Universidade de São Paulo, Ribeirão Preto.

Barros E 1996. Política de saúde no Brasil: a universalização tardia como possibilidade de construção do novo. Ciência \& Saúde Coletiva 1(1):5-17.

Berlinguer G 1978. Medicina e política. Editora Hucitec, São Paulo.

Birman J 1991. Apresentação: interpretação e representação na saúde coletiva. PHYSIS Revista de Saúde Coletiva 1(2):7-22.

Brasil. Ministério da Saúde 1990. Modelos assistenciais no SUS. Brasília.

Campos GWS 1991. A saúde pública e a defesa da vida. Editora Hucitec, São Paulo.

Campos GWS 1992. Reforma da reforma repensando a saúde. (1 $1^{\text {a }}$ ed.). Editora Hucitec, São Paulo.

Fleury S (org.) 1997. Saúde e democracia: a luta do CEBES. Lemos Editorial, São Paulo.

Giovanella L \& Fleury S 1995. Universalidade da atenção à saúde: acesso como categoria de análise, pp.177198. In C Eibenschutz (org.). Política de saúde: o público e o privado. Fiocruz, Rio de Janeiro.
Gramsci A 1995. Os intelectuais e a organização da cultura. (Tradução de Carlos Nelson Coutinho). (9a ed.). Editora Civilização Brasileira, Rio de Janeiro.

Herzlich C 1991. A problemática da representação social e sua utilidade no campo da doença. PHYSIS Revista de Saúde Coletiva 1(2):23-36.

Mendes EV (org.) 1994. Distrito sanitário, o processo social de mudança das práticas sanitárias do Sistema Único de Saúde. (2a ed.). Editora Hucitec, São Paulo.

Mendes Gonçalves RB 1992. Práticas de saúde: processos de trabalho e necessidades. Centro de Formação dos Trabalhadores em Saúde da Secretaria Municipal da Saúde, São Paulo. (Cadernos CEFOR, 1 - Série Textos).

Minayo MCS 1993. O desafio do conhecimento, pesquisa qualitativa em saúde. (2a ed.). Editora Hucitec, São Paulo.

Peduzzi M 1998. Equipe multiprofissional de saúde: a interface entre trabalho e interação. Tese de doutorado. Faculdade de Ciências Médicas. Universidade Estadual de Campinas, Campinas.

Trivinõs ANS 1992. Introdução à pesquisa social em ciências sociais: a pesquisa qualitativa em educação. Editora Atlas, São Paulo.

Artigo apresentado em 10/11/2002

Aprovado em 9/12/2002

Versão final apresentado em 16/7/2003 